\title{
Electrical Energy Quality Analysis in Hospital Centres
}

\author{
Abdourahimoun Daouda*, Sani Idi Boubabacar, Moctar Mossi Idrissa, Saidou Madougou \\ Laboratoire d'Energétique, d'Electronique, d'Electrotechnique, d'Automatique et d'Informatique Industrielle, Université Abdou \\ Moumouni, Niamey, Niger \\ Email: *daoudaabdourahimoun@gmail.com
}

How to cite this paper: Daouda, A., Boubabacar, S.I., Mossi, M.I. and Madougou, S. (2021) Electrical Energy Quality Analysis in Hospital Centres. Smart Grid and Renewable Energy, 12, 53-63.

https://doi.org/10.4236/sgre.2021.124004

Received: April 5, 2021

Accepted: April 27, 2021

Published: April 30, 2021

Copyright (c) 2021 by author(s) and Scientific Research Publishing Inc. This work is licensed under the Creative Commons Attribution International License (CC BY 4.0).

http://creativecommons.org/licenses/by/4.0/

(c) (i) Open Access

\begin{abstract}
Today, energy is a vital component in the functioning of a hospital. Hospital technical facilities have several types of technologies, these include appliances for use; examination apparatus. So, for Quality Health Care in a hospital, there is a need to ensure the proper functioning of hospital equipment. In addition to the required maintenance as specified by the device manufacturer, the quality of the electrical energy across the device must be ensured. This article is an analysis of the quality of electric energy at the substation of National Hospital of Niamey. Thereby, the data collection, followed by the data processing and analysis revealed the parameters characterizing the quality of electrical energy across the substation. Our studies have shown that the substation is underutilized as the maximum inrush current is less than half the available current. The current was consumed by the three phases has resulted in a strong current unbalance $(230 \mathrm{~A})$. However, the current unbalance and the voltage amplitude, are admissible accordingly base on EN50160 standard. Furthermore, the harmonics voltages present in this medium are in the accepted range (1.8\%) according to IEEE 519 standard. However, the fundamental frequency does not meet the standard, but the difference obtained has no adverse effect.
\end{abstract}

\section{Keywords}

Analysis, Quality of Electrical Energy, Distribution Network, Current Unbalance, Harmonic Disturbance

\section{Introduction}

Today, most African countries face a significant lack of access to quality electrical energy. Indeed, in fact, the problem of electric energy distribution in Africa is characterized by poor energy management [1]. This makes it difficult to guaran- 
tee a permanent balance between supply (production of electricity) and demand (subscribers).

Niger has great potential for primary energy (uranium, oil, coal, etc.) but still enables to ensure quality and sufficient electric energy [2] [3]. There is also an increasingly seeing significant use of non-linear loads in the domestic, industrial, and hospital sectors. Which include: laundry machines, X-ray equipment, operating room equipment, screen televisions, air conditioners, mobile phone computers, etc.

In hospitals, almost all activities depend on electricity. This is due to medical activities (examinations, consultations, and oxygen production). Thus, energy is an essential element in running a hospital [4].

These loads are sources of energy quality distortion since even if the supplied voltage to these devices is sinusoidal; the current absorbed by this electrical equipment is not [5]. Also, to ensure good patient care, or simply put for a quality health care system, one must necessarily ensure a continuous supply of qualitative electrical power across hospital devices.

Indeed, several studies and research have been carried out regarding quality improvement from electrical supervision, to the use of disturbance correction techniques, then the use of artificial intelligence, finally to the application of energy transition [6].

In [7], the existence of electrical harmonics in the hospital domain is proven. This disturbance is but one factor in the deterioration of the quality of the electrical energy.

The benefit of this article lies in the establishment of a diagnosis regarding the quality of power supplied to Amirou Boubacar Diallo National Hospital of Niamey. For this, a computation for the electricity quality assessment will be, this theory will help to better control the measured electrical variables with FLUKE 1735 power analyzer, then the measurement techniques used for the data collection and processing be specified, finally the article will match the results to be analyzed and interpreted.

\section{Theory on the Quality of Electrical Energy}

The concept of the quality of electrical energy is diverse. This is why there are different definitions depending on the problem that the author encounters in his relevant network. The most complete definition is that which will take into account all the electrical disturbances that may alter the contractual values set as standard. Thus, one can say that the quality of electricity is defined by four different concepts but all together at a time: supply continuity, voltage wave quality, stability of the frequency and voltage balance [8].

\subsection{Network Quality Standards}

The EN 50160 and IEEE 519 standards respectively specify guidelines on the magnitudes of voltages and permissible harmonic content in the network distri- 
butions low and medium voltage [9].

\subsubsection{EN 50160 Standard}

This standard sets the quality of the supply voltage provided mainly by four electrical variables (the rms value, the unbalance, the frequency and the rate of distortion) [8].

\section{1) The voltage effective value}

Like other indicators, voltage characterizes the correct functioning of a power source in amplitude. Across this power source must be acceptable values for the correct operation of the devices connected to it. The low voltage that corresponds to the electrical distribution network is either evaluated as phase-to-phase (phase-phase) or single (phase-neutral) voltage. For phase-to-neutral voltage, EN50160 standard sets the admissible level of $r m s$ voltage at $230 \mathrm{~V} \pm 10 \%$. The latter is based on:

$$
V_{R M S}=\sqrt{\frac{1}{T} \int_{0}^{T} v^{2} \mathrm{~d} t}
$$

\section{2) The voltage unbalances}

There is voltage unbalance in a distribution network when the voltages supplied across the generator do not have the same effective value at a time. Note that this voltage unbalance is mainly caused either by a network line impedance asymmetries or current inequalities in distribution lines. The permissible unbalance rate on low voltage networks must be below 2\% according to EN 50160 standard, the unbalance is calculated by applying the following formula [9]:

$$
T_{D U}=\frac{\max \left(V_{i}-V_{a v}\right)}{V_{a v}}
$$

$$
\left\{\begin{array}{l}
V_{i} \text { beeing the phase voltage } i \text { and } i=1,2,3 \text { for a triphase system. } \\
V_{A V}=\frac{\sum_{i=1}^{3} V_{i}}{3}
\end{array}\right.
$$

\section{3) The frequency}

In case of electricity production by an alternator, it is necessary to keep the frequency of the synchronous power source at a fixed value, if not the electrical device will attend premature deterioration. The frequency of a power source is defined by the number of cycles per second. It is limited to $50 \mathrm{HZ} \pm 1 \%$ according to the European Standard.

\section{4) The voltage distortion rate}

The Total Harmonic Distortion is calculated using Equation (3) [7]:

$$
\operatorname{THD}(\%)=100 \frac{\sqrt{\sum_{n=2}^{n=\infty} Y_{n}^{2}}}{Y_{1}}
$$

The contractual value of this rate depends on the load and the electrical system. For a study purpose at the global node, IEEE 519 standard sets the disturbance limit. 


\subsubsection{IEEE 519 Standard}

For the low voltage network, contractual values are fixed by IEEE std 519 to prevent harmonic disturbances effects. Thus, the limits of the Global Harmonic Rate in a $120 \mathrm{~V}$ to $69 \mathrm{kV}$ voltage in a distribution network in a hospital environment is limited to $3 \%$ [7].

\subsection{Principle of Data Acquisition}

The choice of the site for evaluating the quality of the electricity is determined by the voltage supply node, in the case of Amirou Boubacar Diallo National Hospital, the corresponding node is the secondary of the transformer substation. The technical specifications thereof are specified in the following Table 1:

The coupling of this transformer being Triangle-Star, hence for a reliable study on the substation, the required connection is as illustrated in Figure 1.

\section{Results}

The curves of the main parameters in the diagnosis of our hospital site are the result of a four days long data collection process. Ultimately, the results in this article will be interpreted in accordance to the above detailed EN 50160 and IEEE-5019 standard.

Table 1. Technical specifications of the substation.

\begin{tabular}{cc}
\hline Characteristics & Values \\
\hline Apparent power & $1000 \mathrm{KVA}$ \\
Short-circuit voltage & $5 \%$ \\
Coupling & Dyn11 \\
Primary voltage & $20 \mathrm{KV}$ \\
Secondary voltage & $400 \mathrm{~V}$ \\
Frequency & $50 \mathrm{HZ}$ \\
Secondary current & 1443 \\
\hline
\end{tabular}

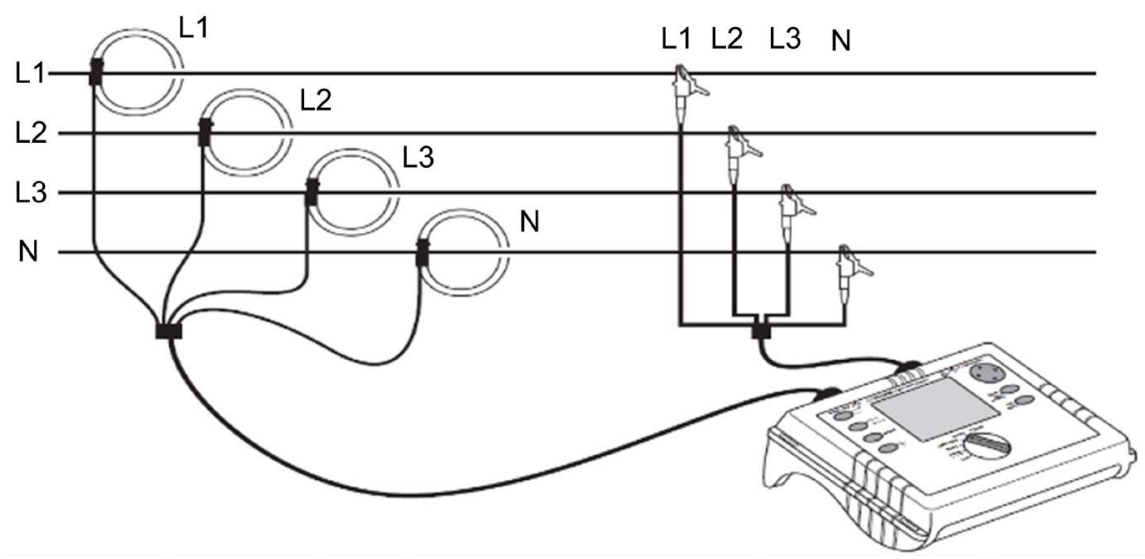

Figure 1. Connecting the analyzer to the substation secondary. 


\subsection{Phase-to-Phase Voltage Profile}

The voltage curves are as follows:

Figure 2 shows a phase-to-neutral voltage measuring result carried out on four days period. Looking at the curves in Figure 2, it's clear that on the three phases the variations are identical and have similar behaviors (cuts and instabilities of the voltage amplitude), which by the way actually proves what has been mentioned earlier (the facility is supplied by the same substation). Furthermore, voltage fluctuations evaluated are represented in Figure 3. Compared to the contractual values $( \pm 23 \mathrm{~V})$ of EN50160 standard (the determined deviations are admissible except for a case recorded in the morning).

The experienced voltage fluctuation is due to the use made (power consumption) on this substation. As a result, the currents trend curve analysis Figure 4 will help to better understand these voltages voltage.

\subsection{Current Profile}

In Figure 4, the curves showing the effective current values reveal two peaks of consumption (maximum and minimum) during the day.

The maximum peak of the site's daily consumption was recorded around midday. The level of this current is not the same on the four power lines, the Table 2 summarizes the corresponding values by phase.

The first obvious interpretation to be inferred from this table is that the maximum electric currents through the three phases do not occur at the same times. This is due to the distribution of devices according to the department specialty. These include Emergency department and operating theaters. Also, in addition to the medical analysis and examination devices, there are energy-

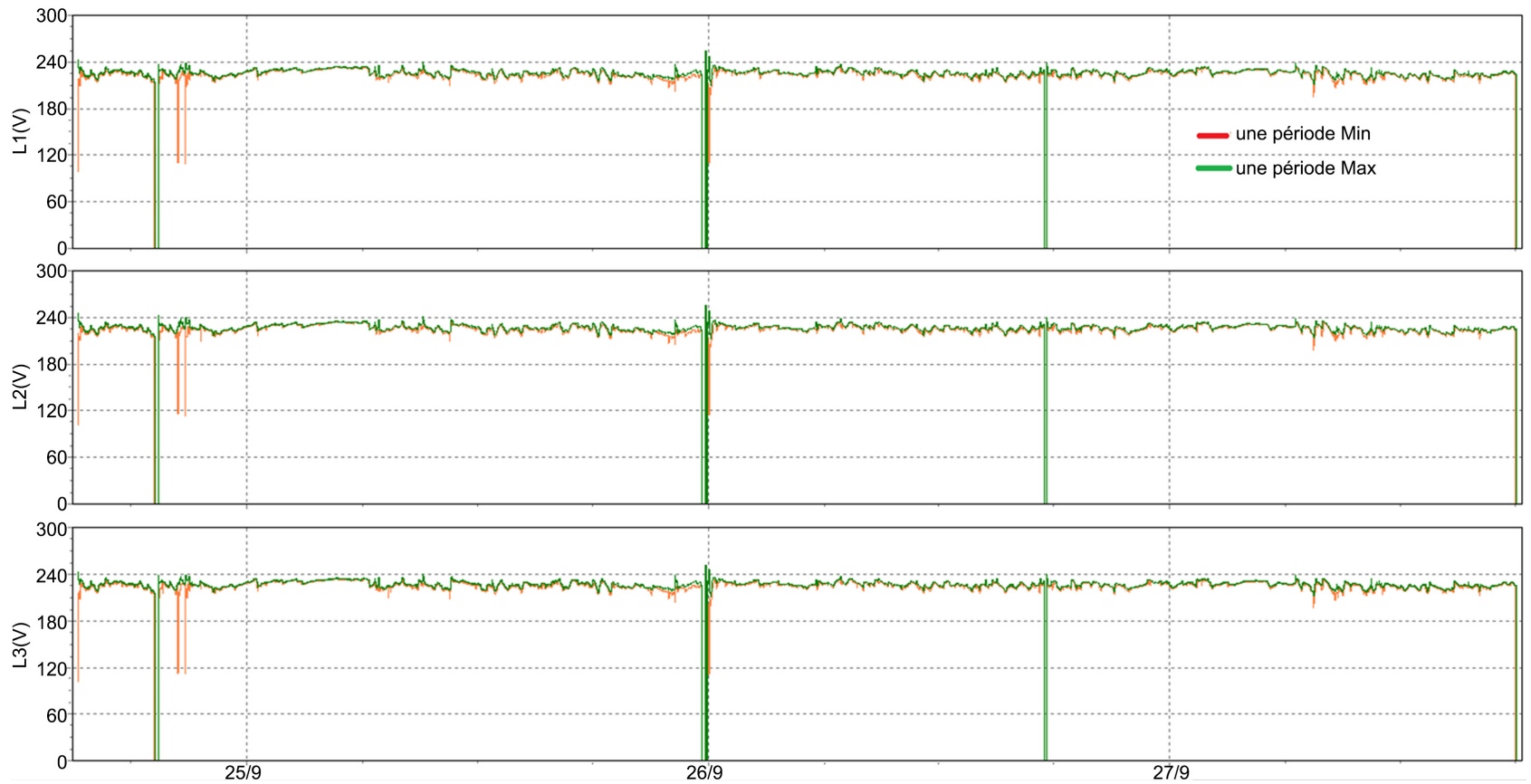

Figure 2. Shapes of phase-to-neutral voltages. 

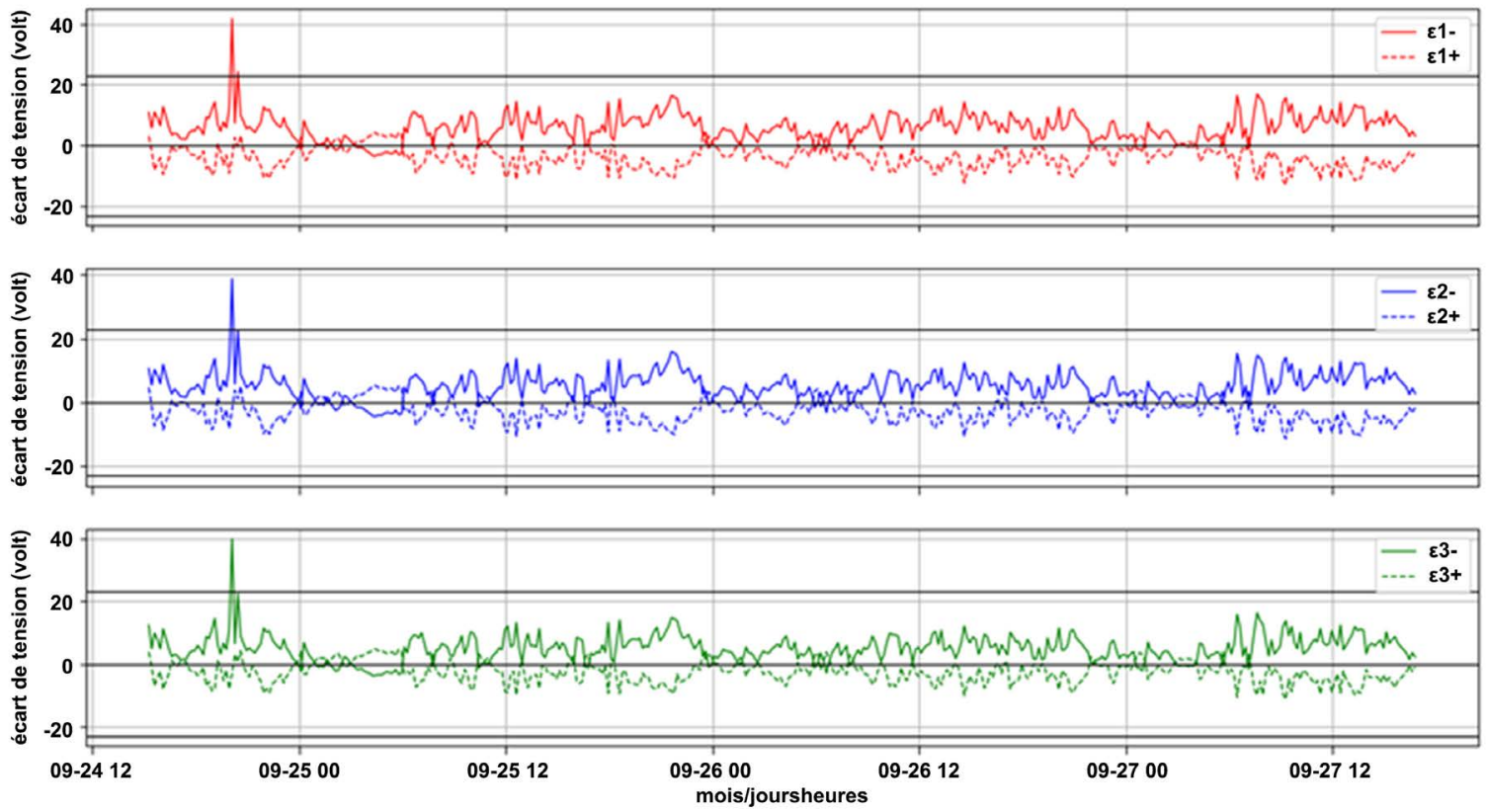

Figure 3. Deviations of the voltages measured from the nominal voltage.

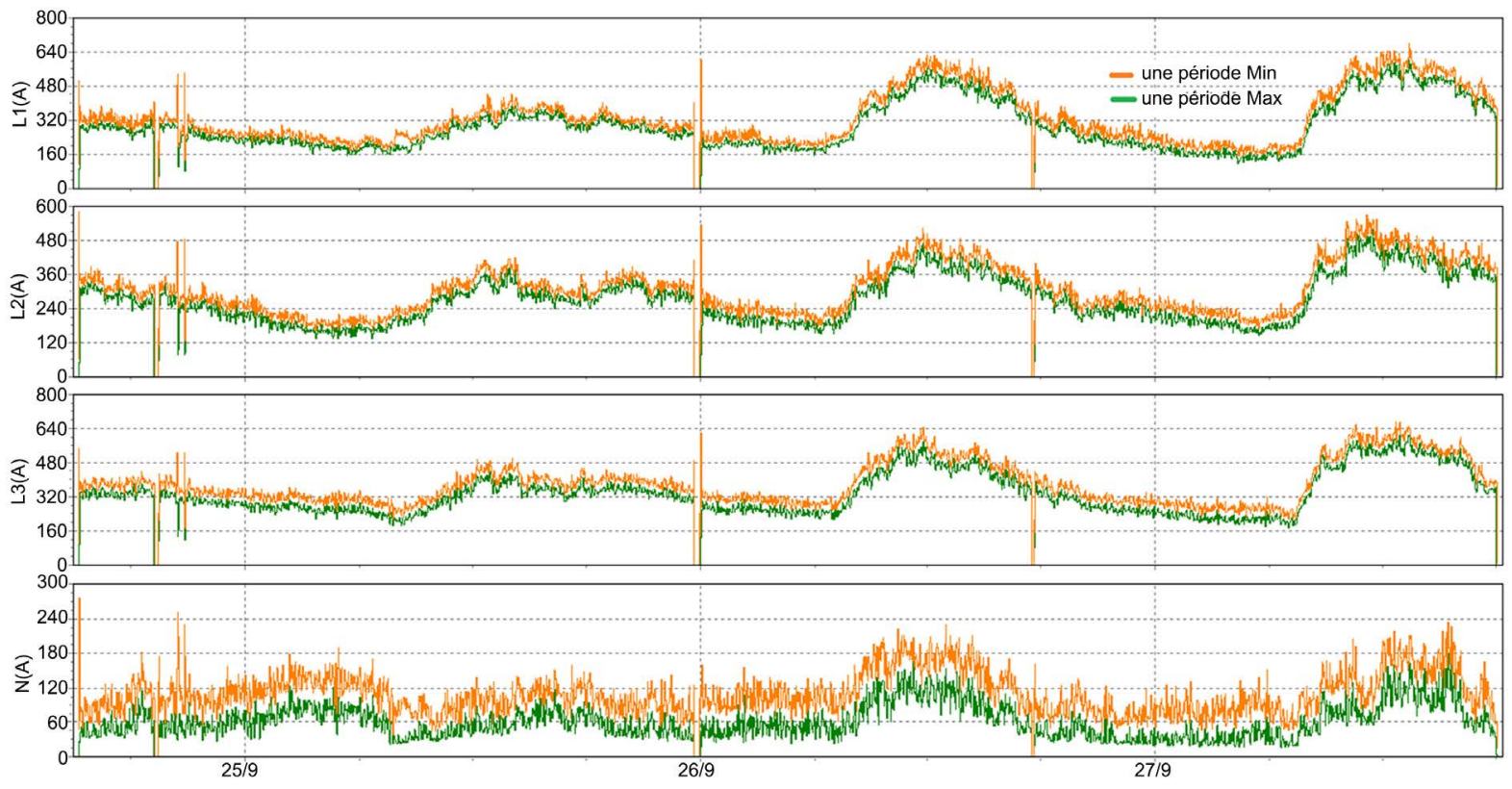

Figure 4. Trends in electricity consumption.

Table 2. The currents maximum values in the phases.

\begin{tabular}{ccccc}
\hline Lines & Variables & Sunday & Monday & Tuesday \\
\hline \multirow{2}{*}{ Phase 1 } & $\mathrm{I}_{1}(\mathrm{~A})$ & 500,727 & 599,318 & 602,864 \\
& $\mathrm{~T}_{1}$ (h:min:s) & $2: 09: 12(\mathrm{Pm})$ & $12: 22: 32$ & $13: 25: 52$ \\
Phase 2 & $\mathrm{I}_{2}(\mathrm{~A})$ & 420.408 & 468.955 & 568,364 \\
& $\mathrm{~T}_{2}$ (h:min:s) & $2: 15: 52(\mathrm{Pm})$ & $11: 47: 32$ & $11: 10: 52$ \\
Phase 3 & $\mathrm{I}_{2}(\mathrm{~A})$ & 500,727 & 627,545 & 617,727 \\
& $\mathrm{~T}_{3}$ (h:min:s) & $2: 07: 32(\mathrm{Pm})$ & $11: 50: 52$ & $12: 42: 32$ \\
\hline
\end{tabular}


consuming equipment (splits and air conditioners) during this period which happens to be break time. At 4 p.m., the curves decrease over all the phases until the next day around 7 a.m., this is the period at which happens the second changeover corresponding to low consumption (see Table 3). After this switch point, a new current increment begins until the first peak (end of 24 hours cycle).

Regarding the neutral currents from Table 4, it appears that the load distribution is not balanced and strong neutral currents increase the overheating (insulation) of the transformer, therefore premature aging of this element [10]. However, it can be mitigated using unbalance compensators [11].

\subsection{Voltage Unbalance}

The calculated voltage unbalances are shown on the curves in Figure 5.

Throughout the measurement period, the unbalance rates recorded are lower than the EN50160 nominal rate (2\%). These results can be explained by the fact that the maximum current consumed on this substation is approximately $43 \%$ of the available secondary current. So, the cause of this voltage unbalance (the neutral current) is subjected to a high impedance of the transformer.

Although voltage unbalances do not significantly impact the voltage amplitude, the current unbalances shown in Figure 6 are significant since they exceed the typical values required by IEEE 11592009 standard.

\subsection{Frequency}

The synchronism of the power generation source powering the hospital center via the substation is shown in Figure 7.

The temporal evolution of the frequency is characterized by two patterns: it is

Table 3. The minimum values of the currents in the phases.

\begin{tabular}{ccccc}
\hline Lines & Settings & Sunday & Monday & Tuesday \\
\hline \multirow{2}{*}{ Phase 1} & $\mathrm{I}_{1}(\mathrm{~A})$ & 160,364 & 154,364 & 128.182 \\
& $\mathrm{~T}_{1}$ (h:min:s) & $05: 37: 00 \mathrm{am}$ & $06: 00: 52 \mathrm{am}$ & $06: 30: 32 \mathrm{am}$ \\
\multirow{2}{*}{ Phase2 } & $\mathrm{I}_{2}$ (A) & 132.818 & 153.409 & 145,500 \\
& $\mathrm{~T}_{2}$ (h:min:s) & $04: 40: 52 \mathrm{am}$ & $06: 17: 32 \mathrm{am}$ & $05: 30: 52 \mathrm{am}$ \\
Phase3 & $\mathrm{I}_{3}$ (A) & 183.545 & 216.409 & 172,092 \\
& $\mathrm{~T}_{3}$ (h:min:s) & $07: 49: 12 \mathrm{am}$ & $07: 00: 52 \mathrm{am}$ & $07: 04: 12 \mathrm{am}$ \\
\hline
\end{tabular}

Table 4. The maximum and minimum values of the neutral currents.

\begin{tabular}{ccccc}
\hline Lines & Settings & Sunday & Monday & Tuesday \\
\hline \multirow{2}{*}{ Maximum } & $\mathrm{I}_{\mathrm{N}}(\mathrm{A})$ & 189,680 & 230 & 202,909 \\
& $\mathrm{~T}_{\mathrm{N}}(\mathrm{h}: \mathrm{min}: \mathrm{s})$ & $0: 57: 32 \mathrm{am}$ & $1: 00: 52 \mathrm{pm}$ & $3: 30: 52 \mathrm{pm}$ \\
& $\mathrm{I}_{\mathrm{N}}(\mathrm{A})$ & 23.045 & 23,000 & 17.864 \\
\multirow{2}{*}{ Minimum } & $\mathrm{T}_{\mathrm{N}}(\mathrm{h}: \mathrm{min}: \mathrm{s})$ & $07: 49: 22 \mathrm{am}$ & $04: 49: 12 \mathrm{am}$ & $07: 02: 32 \mathrm{am}$ \\
\hline
\end{tabular}




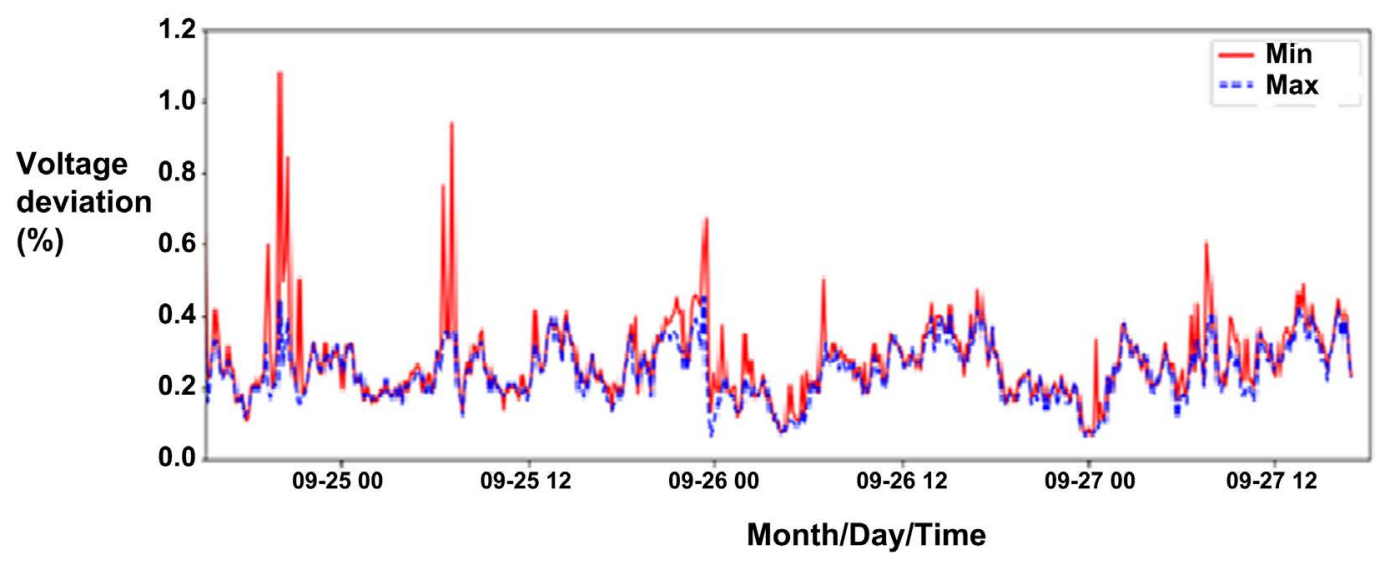

Figure 5. Voltage unbalances rates.

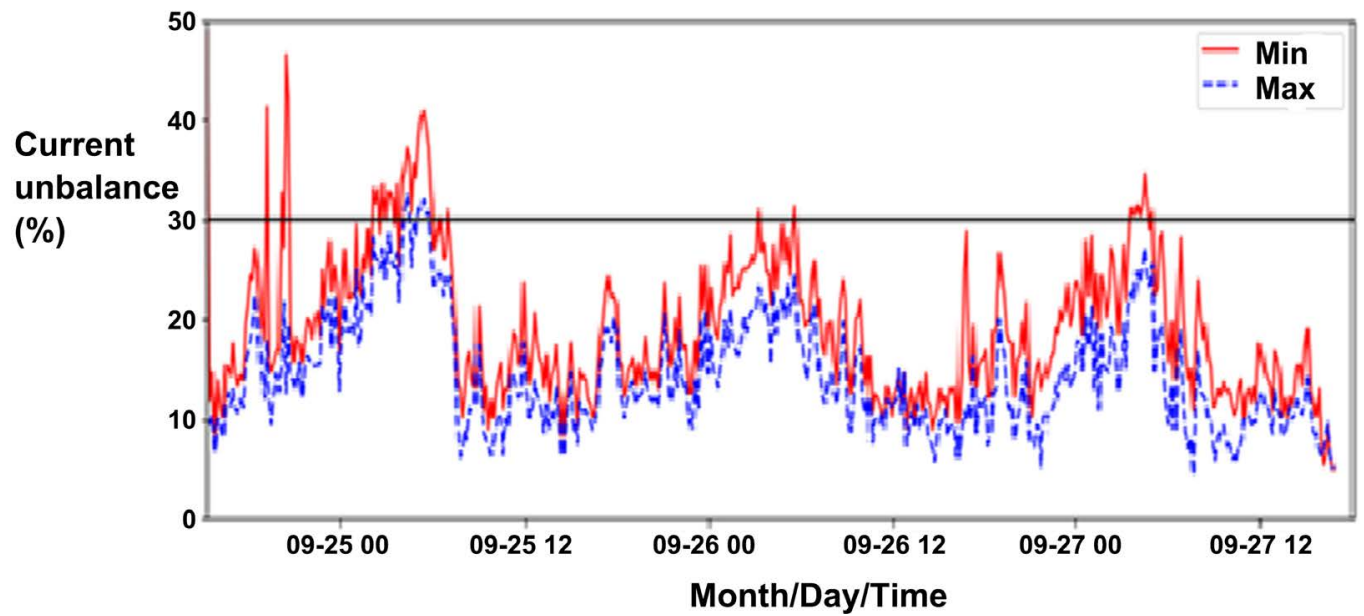

Figure 6. Current unbalance rates.

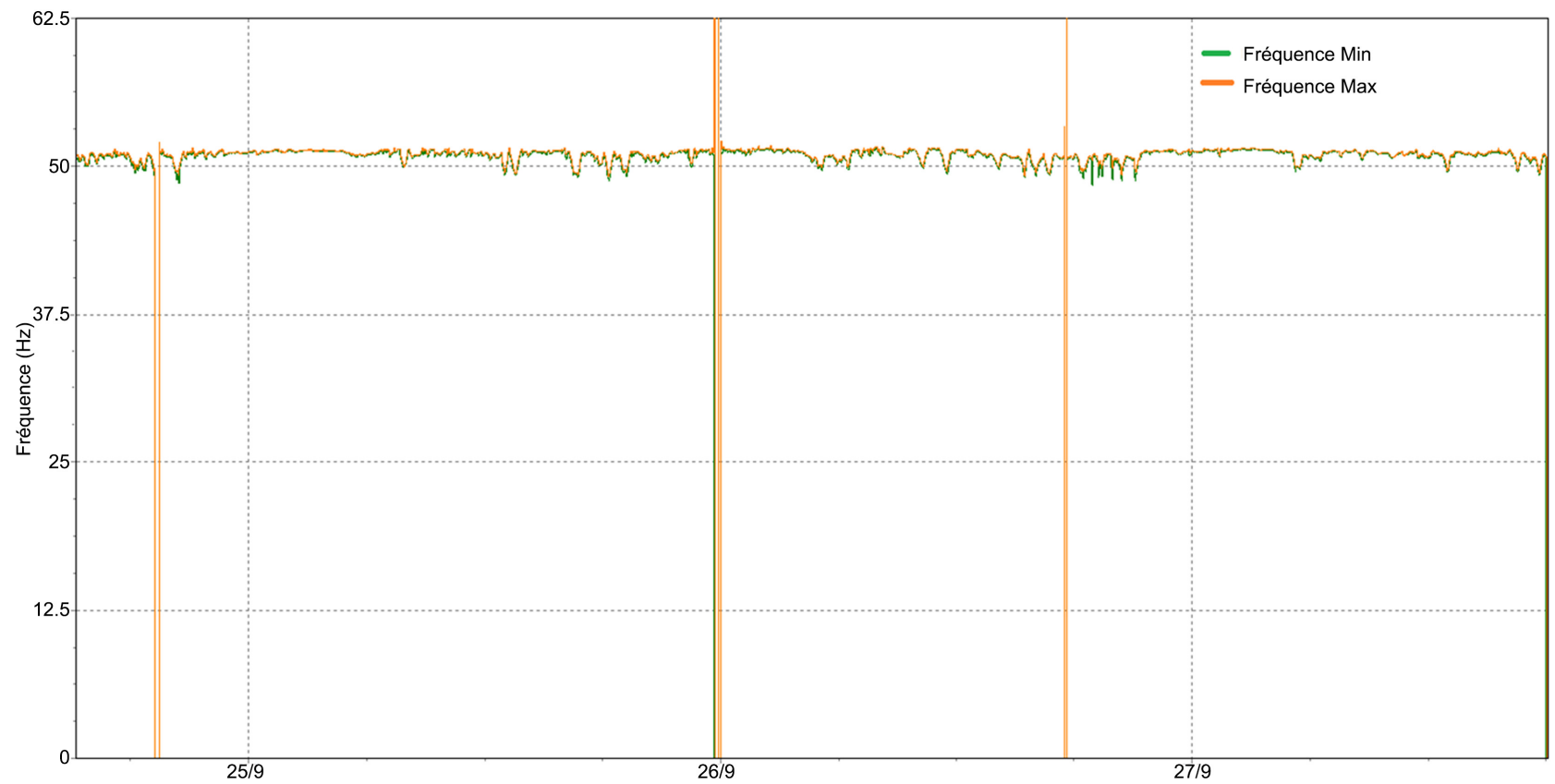

Figure 7. Variation of the measured minimum and maximum frequency. 
asymptotically stable at the start of the day and unstable over the remaining hours. It will be too early to explain these frequency patterns without a glance to the corresponding harmonic level (Figure 9), since it is the main disturbance that directly affects the pitch. However, an assessment of the admissible frequency range is possible with the help of Figure 8, illustrating the recorded frequency tolerance ranges and the EN 50160 standard. The frequency of the voltage distributed to the site fails to be of acceptable quality.

\subsection{Profile of the Harmonic Rate in Voltage and Current}

Indeed, by analyzing, the curves of Figure 9 representing the harmonic level of voltages and currents. It appears that the low levels of these variables correspond to the period of pitch stability and the important THD takes shape in the time intervals of the identified frequencies instability.

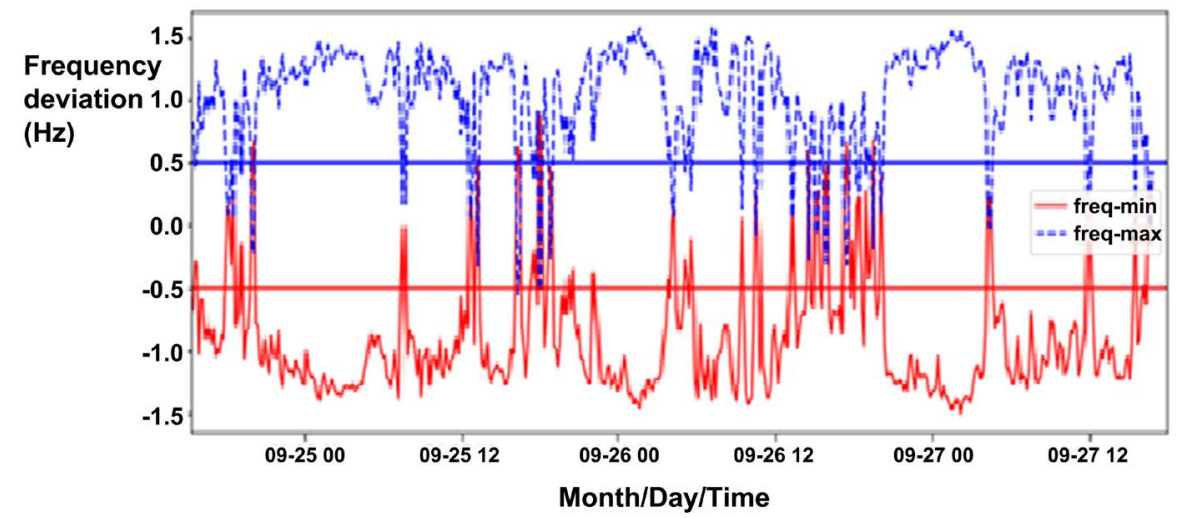

Figure 8. Deviations of minimum and maximum frequencies from the nominal frequency.

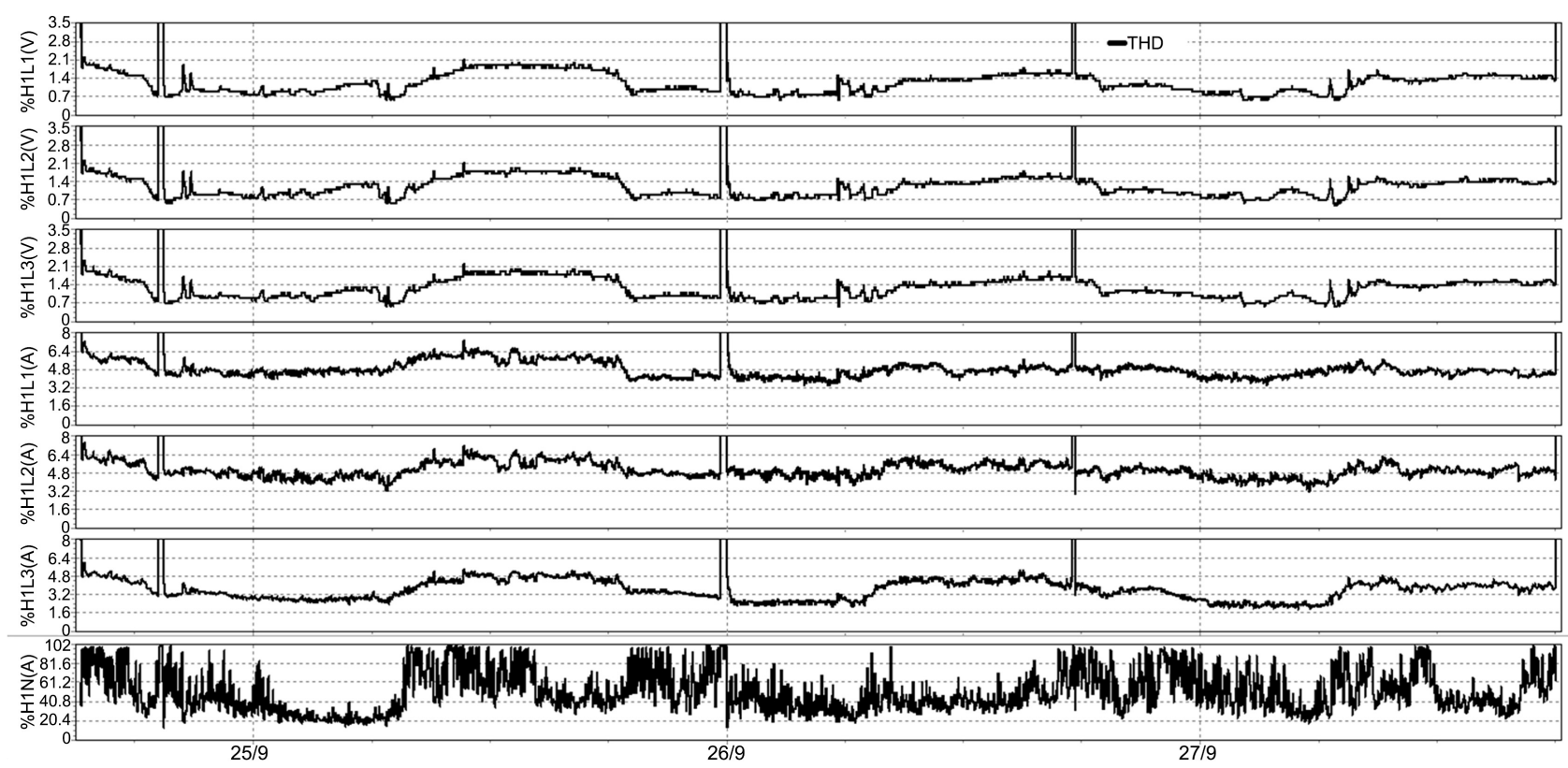

Figure 9. Profile of the harmonic rate in voltage and current. 


\section{Conclusions}

The diagnostic of the quality of the electric power distributed to Amirou Boubacar Diallo National Hospital Center was carried out on four indices: the amplitudes of the voltage, the voltage unbalance, the stability of the voltage frequency, and the form of voltage waves. The effective values of the voltages are unstable but fall into the tolerance interval set by the EN 50160 standard. The voltages unbalance is also acceptable but the currents unbalance is very important ranging from $4.25 \%$ to $46.38 \%$. This fact can be explained by the low utilization rate of the electric transformer, which is around $43 \%$.

The frequency deviation is very critical, with a $1.5 \mathrm{~Hz}$ exceedance. This greatly exceeds the deviation fixed by the standard. This article also made it possible to observe that large differences in fundamental frequency occur at the same time periods as large harmonic distortion rates. These THDs are eligible base on 519.Std IEEE standard.

Another contribution of this work lies in the fact that the recorded electricity consumption corresponds exactly to the work schedules in this hospital center. So, it will be very important to develop an intelligent system to assess health care workers' electricity consumption.

\section{Conflicts of Interest}

The authors declare no conflicts of interest regarding the publication of this paper.

\section{References}

[1] Falisoa, R.L. (2013) Étude de commandes non linéaires pour réseaux électriques application a un système SMIB. Doctoral Thesis, Antsiranana University, Madagascar, $183 \mathrm{p}$.

[2] Ministry of Energy and Petroleum (2015) Système d'information énergétique (SIE), Direction de l'Energie, Ministère de l'énergie et du pétrole. Niamey-Niger, $43 \mathrm{p}$.

[3] Nigerien Electricity Company-NIGELEC (2015) Rapport définitif du plan d'actions de réinstallation du projet de renforcement et d'extension des réseaux électriques des villes de Niamey. Dosso, Maradi, Zinder, Tahoua, Agadez et Tillabéri, 120 p.

[4] Sallam, A.A. and Malik, O.P. (2018) Electric Distribution Systems. John Wiley \& Sons, Inc., Canada. https://doi.org/10.1002/9781119509332

[5] Frelin, W. (2009) Impact de la pollution harmonique sur les matériels de réseau. Doctoral thesis, University of Paris Sud 11, Paris, France, 156 p.

[6] Jiang, X., Stephen, B., and McArthur, S.D. (2020) Automated Distribution Network Fault Cause Identification with Advanced Similarity Metrics. IEEE Transactions on Power Delivery, 36, 785-793. https://doi.org/10.1109/TPWRD.2020.2993144

[7] Daouda, A., Madougou, S. and Ibrahim, A.A. (2017) Global Harmonic Rate Assessment in the Electricity Distribution Network in Niamey City: Case Studies of Domestic, Industrial and Hospital Substations. Energy and Power Engineering, 9, 786-801. https://doi.org/10.4236/epe.2017.912049

[8] Félice, É. and Révilla, P. (2009) Qualité des réseaux électriques et efficacité énergétique. Dunod, Paris, 198 p. 
[9] L'appareillage, B.T. (2009) Règles générales de conception d'une installation électrique (Chapitre A). Schneider Electric-Guide to Electrical Installation.

[10] Singh, R., \& Singh, A. (2010) Aging of Distribution Transformers Due to Harmonics. Proceedings of 14th International Conference on Harmonics and Quality of Power-ICHQP2010, Bergamo, Italy, 26-29 September 2010. https://doi.org/10.1109/ICHQP.2010.5625347

[11] Liu, Y., Zeng, X., Chen, D., Liu, Z., Zhang, X. and Wang, X. (2017) A Novel ThreePhase Imbalanced Overvoltage Suppression Method for Distribution Network. 2017 China International Electrical and Energy Conference (CIEEC), Beijing, China, 25-27 October 2017, 538-542. https://doi.org/10.1109/CIEEC.2017.8388505 